\title{
ĐIỂM VÔI HOÁ VÀ MỨC Độ HẸP MẠCH VÀNH TRÊN CẮT LỚP VI TÍNH 256 DÃY
}

\begin{abstract}
Nguyễn Đình Min
TÓM TẮT

Mục tiêu: nghiên cứu sự liên quan giữa điểm vôi hoá và mức độ hẹp động mạch vành trên CLVT 256 dãy. Đối tượng và phương pháp: Nghiên cứu mô tả cắt ngang $150 \mathrm{BN}$ chẩn đoán bệnh mạch vành được chụp CLVT 256 dãy động mạch vành tại Bệnh viện Hữu nghi Việt Đức từ 1/7 đến 30/7/2020. Kết quả:

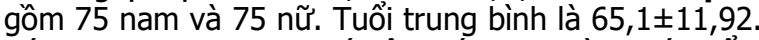
Có $86 / 150(57,3 \%)$ BN có vôi hoá mach vành với điểm vôi hoá trung bình là 351,2ะ529,47 (từ 1- 2652 điểm). Điểm vôi hóa trung bình của các $B N<60$ tuổi là $46,5 \pm 144,35$ và của các $B N \geq 60$ tuổi là $274,2 \pm 504.28$ $(P=0,003)$. Điểm vôi hóa trung bình của các $B N$ hẹp mạch vành $\geq 50 \%$ là $691,9 \pm 674,61$ và hẹp $<50 \%$ là $117,4 \pm 173,58(p<0,001)$. Đường cong ROC biểu thi liên quan điểm vôi hoá và mức độ hẹp mạch vành $\geq 50 \%$ có diện tích dưới đường cong (AUC) là 0,829 (95\%CI: $0,740-0,919)$ với $p<0,001$. Điểm vôi hoá cutoff $=196$ điểm với Sensitivity $=0,706$ và 1Specificity=0,173. Kết luận: Điểm vôi hóa mạch vành liên quan đến mức độ hẹp nên có khả năng dự báo nguy cơ tai biến do bệnh mạch vành trong tương lai.
\end{abstract}

Tư khoá: vôi hoá mạch vành, bệnh mạch vành, cắt lớp vi tính.

\section{SUMMARY}

\section{CORONARY CALCIFICATION SCORE AND STENOSIS ON 256-SLICE MSCT IMAGING}

Objects: Study the relation of calcification score and coronary stenosis on 256-slice CT. Materials and Methods: cross-sectional-decritive study in 150 patients diagnosed of coronary diseases had coronary artery angiogram on 256-slice CT at Vietduc friendship hospital from $1 / 7$ to30/7/2020. Results: : including 75 male and 75 female, mean ages was $65.1 \pm 11.92$. There was $86 / 150(57.3 \%)$ cases having coronary calcification with mean calcification score of $351.2 \pm 529.47$ (from 1 to 2652). Mean score of $<60$ aged group was $46.5 \pm 144.35$ and $274.2 \pm 504.28$ in 60 and over aged group $(p=0.003)$. Mean calcification score of $50 \%$ and over stenosis was $691.9 \pm 674.61$ and under $50 \%$ stenosis was $117.4 \pm 173.58$ $(p<0.001)$. The ROC showed the correlation of calcification score and $\geq 50 \%$ stenosis had AUC of 0.829 (95\%CI: $0.740-0.919)$ with $p<0.001$. The cutoff calcification score was 196 with Sensitivity $=0.706$ and 1-Specificity=0.173. Conclusion: Coronary calcification score had correlation with stenosis then be possible to predict the coronary events in the future.

\section{*Bệnh viện hữu nghi Việt Đức}

Chịu trách nhiệm chính: Nguyễn Đình Minh

Email: minhdr24@gmail.com

Ngày nhận bài: 13.11 .2020

Ngày phản biện khoa học: 4.01.2021

Ngày duyệt bài: 15.01.2021
Keywords: coronary calcification, coronary disease, CT-Scanner.

\section{I. ĐĂT VẤN ĐỀ}

Bệnh động mạch vành là nguyên nhân gây tử vong hàng đâuu ở một số nước. Chụp mạch vành (Catheter coronary angiography-CCA) được xem là tiêu chuẩn vàng để chẩn đoán vị trí, mức độ hẹp lòng mạch. Tuy nhiên, chụp mạch vành không thể chỉ định cho tất cả các trường hợp nghi ngờ bệnh mạch vành vì đây là thủ thuật xâm lấn và có nhiều nguy cơ. Do đó, chụp cắt lớp vi tính (CLVT) mạch vành có thể được xem là phương pháp thăm khám thay thế cho CCA. Cắt lớp vi tính đa dãy động mạch vành được ứng dụng một cách rộng rãi trong thập kỷ qua cho phép chẩn đoán sớm các bệnh lý mạch vành ngày càng chính xác. Cắt lớp vi tính cho phép phát hiện vôi hóa mạch vành, lượng giá mức độ vôi hóa bằng thang điểm vôi hóa (Agatston score). Mức độ vôi hóa mạch vành thường liên quan đến mức độ xơ vữa gây hẹp lòng mạch. Phát hiện sớm các trường hợp hẹp nặng nhằm lập kế hoạch điều trị chính xác hơn đồng thời loại trừ các trường hợp hẹp nhẹ không cân làm thềm các thăm khám khác giúp hạn chế nguy cơ và kinh phí.

Do vậy, chúng tôi thực hiện nghiên cứu "Điểm vôi hóa và mức độ hẹp mạch vành trên chụp cắt lớp vi tính 256 dãy" nhằm đánh giá sự liên quan giữa mức độ vôi hóa và hẹp động mạch vành trên chụp cắt lớp vi tính 256 dãy tại bệnh viện hữu nghị Việt Đức.

\section{II. ĐỐI TƯỢNG VÀ PHƯƠNG PHÁP NGHIÊN CỨU}

2.1. Đối tượng nghiên cứu: Gồm 150 bệnh nhân (BN) có nghi ngờ bệnh mạch vành được chụp CLVT 256 dãy mạch vành tại khoa Chẩn đoán hình ảnh - Bệnh viện hữu nghị Việt Đức trong tháng 7/2020.

- Tiêu chuẩn lựa chọn bệnh nhân: BN được chụp CLVT-256 dãy mạch vành, có đo điểm vôi hóa, tuổi từ 18 trở lên, không phân biệt giới tính.

- Tiêu chuấn loại trừ: không đưa vào nghiên cứu các trường hợp như: chất lượng hình ảnh CLVT-256 không đạt yêu câu, đã được đặt stent mạch vành hoặc can thiệp nong mạch vành trước đó, sau phẫu thuật lồng ngực.

2.2. Phương pháp nghiên cứu:

- Phương pháp nghiên cứu: Nghiên cứu hồi 
cứu mô tả cắt ngang.

- Phương tiện nghiên cứu: Máy chụp Cắt lớp vinh tính 256 dãy của GE có phân mềm dựng ảnh và đo đạc mach vành.

- Quy trình chụp CLVT-256 mạch vành: bệnh nhân được hướng dẫn nhịn ăn ít nhất 6 giờ trước khi chụp, nhịp tim ổn định được điều chỉnh không quá 90 chu kỳ/phút, không có loạn nhịp tim, không có tiền sử dị ứng với thuốc cản quang i-ốt. Bệnh nhân được đặt đường truyền tĩnh mạch với kim $18 \mathrm{G}$ vào tĩnh mạch nông tay phải. Chụp các lát cắt không tiêm thuốc khu trú vùng tim kéo dài từ nền tim lên đến đỉnh tim để đánh giá độ rõ nét của hình ảnh và tính điểm vôi hóa mạch vành.

Bệnh nhân được tiêm $1,5 \mathrm{ml} / \mathrm{kg}$ thuốc cản quang chứa i-ốt nồng độ $370 \mathrm{mg} / \mathrm{ml}$, tốc độ tiêm $6 \mathrm{ml} / \mathrm{s}$, thời gian bắt đầu tiêm được đặt theo chế độ smart-map, lấy động mạch chủ lên làm chứng. Phân tích hình ảnh theo các chu kỳ tim tại thời điểm thu được chất lượng hình ảnh mạch vành tốt nhất. Xác định điểm vôi hoá mạch vành bằng phần mềm tự động có trong máy chụp. Tái tao hình ảnh động mạch vành và đo đạc trên $2 D$, dựng hình MIP, MPR và VR, đo đạc kích thước mạch máu và mức độ hẹp trên phần mềm duỗi mạch.

- Thống kê và xử lý số liệu: bằng phần mềm SPSS 20.0 .

\section{KẾT QUẢ NGHIÊN CỨU}

\section{1. Đặc điểm chung nhóm nghiên cứu}

- Tuổi và giới tính: gồm 150 BN có 75 nam và 75 nữ, tỷ lệ nam: nữ là $1: 1$. Tuổi trung bình (TTB) của các BN là $65,1 \pm 11,92$; trong đó tuổi trung bình của nam là $62,6 \pm 12,01$ và của nữ là $67,6 \pm 11,27(p=0,01)$.

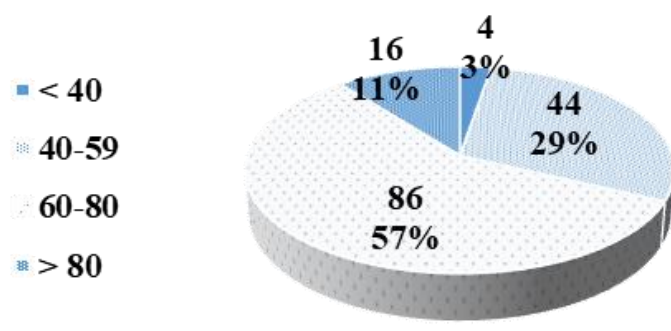

Biểu đồ 1. Đặc điểm phân bố bệnh nhân theo nhóm tuôii.

- Các BN gặp nhiều ở tuổi >40, chiếm 146/150(97,3\%), trong đó nhóm tuổi gặp nhiều nhất 60-80 tuổi, chiếm 86/152(57,3\%).

3.2. Đặc điểm vôi hoá mạch vành trên CLVT - Điểm vôi hoá: có $86 / 150(57,3 \%)$ BN có vôi hoá động mạch vành. Điểm vôi hoá trung bình (VHTB) là 351,2 2529,47 (từ 1- 2652 điểm), trong đó, VHTB của nam là $421.5 \pm 583,37$ và của nữ là $273,8 \pm 448,01(p=0,2)$. Bên cạnh đó, VHTB của các $B N<60$ tuổi là $46,5 \pm 144,35$ và của các

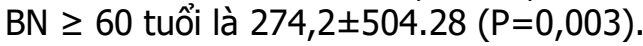

- Mức độ vôi hoá: có $64 / 150(42,7 \%)$ đô 0 (0 điểm); 38/150(25,3\%) độ 1 (1-99); 26/150 (17,3\%) độ 2 (100-399); 13/150(8,7\%) độ 3 (400-999) và 9/150(6\%) độ 4 ( $\geq 1000)$.

- Liên quan điểm vôi hoá và hep mạch vành: điểm VHTB của các $B N$ hep mạch vành $\geq 50 \%$ là $691,9 \pm 674,61$ và hẹp $<50 \%$ là $117,4 \pm 173,58$ $(p<0,001)$. Đường cong ROC biểu thị liên quan điểm vôi hoá và mức độ hẹp mạch vành $\geq 50 \%$ có diện tích dưới đường cong (AUC) là 0,829 (95\%CI: $0,740-0,919)$ với $p<0,001$. Điểm vôi hoá cut-off $=196$ điểm với Sensitivity $=0,706$ và 1 -Specificity $=0,173$.

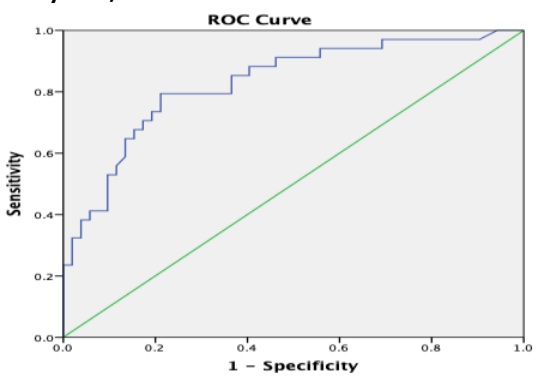

Hình 1. Đường cong ROC biểu thị điểm cutoff liên qua điểm vôi hoá và hẹp động mạch vành $\geq 50 \%$.

\section{BÀN LUÂ̂N}

Cắt lớp vi tính đa dãy được ứng dụng mạnh mẽ trong chụp mạch vành trong những năm gần đây nhằm thay thế cho các thủ thuật xâm lấn như chụp mạch máu (CCA). Đây là thăm khám có thể phát hiện vôi hoá mạch vành và tính điểm vôi hoá theo Agastone Score và đánh giá mức độ hẹp lòng mạch từ đó có chế độ theo dõi hoặc can thiệp hợp lý cho người bệnh.

Trong các nghiên cứu trước đây $[1,3]$, nam giới thường nhiều hơn nữ giới với tỷ lệ nữ thay đổi từ $35-40 \%$. Trong nghiên cứu này, chúng tôi gặp 75 nam và 75 nữ với tỷ lệ nam: nữ là $1: 1$. Như vậy, tỷ lệ nữ trong nghiên cứu của chúng tôi cao hớn so với các nghiên cứu trước đây. Điêuu này có thể do bệnh viện Việt Đức không phải là chuyên tim mạch nên tỷ lệ chưa phản ánh được thực chất tỷ lệ mắc bệnh trong cộng đồng.

Tuổi trung bình của các $\mathrm{BN}$ trong nghiên cứu này là $65,1 \pm 11,92$ tuổi; trong đó TTB của nam là $62,6 \pm 12,01$ và của nữ là $67,7 \pm 11,27$, sự khác 
nhau về TTB giữa hai giới là có ý nghĩa $(p=0,01)$. Phần lớn các $B N$ đều tuổi $>40$ chiếm $97,3 \%$, trong đó lứa tuổi gặp nhiều nhất trong nghiên cứu là $60-80$ tuổi, chiếm 57,3\%. Tuổi trung bình trong các nghiên cứu trước đây là từ 53 đến 60 tuổi $[1,4]$. Như vậy, đối tượng nghiên cứu của chúng tôi có TTB cao hơn so với các nghiên cứu trước đây và nữ giới có tuổi cao hơn nam giới.

Điểm vôi hoá mạch vành dùng để lượng hóa mức độ vôi hoá động mạch vành và dự báo nguy cơ đột quy tim mạch trong tương lai. Điểm vôi hoá mạch vành đã được sử dụng trong vài thập kỷ qua như là dấu hiệu cảnh báo mức độ xơ vữa thành mạch trên phim Xquang hay CLVT đa dãy. Vôi hoá mạch vành còn là dấu hiệu dự báo cho nguy cơ xảy ra đột quy tim mạch. Bên cạnh đó, điểm vôi hoá cao còn liên quan đến nguy cơ ung thư, bệnh thận mãn tính, tràn khí màng phổi, tắc nghẽn đường thở mãn tính và gãy cổ xương đùi.
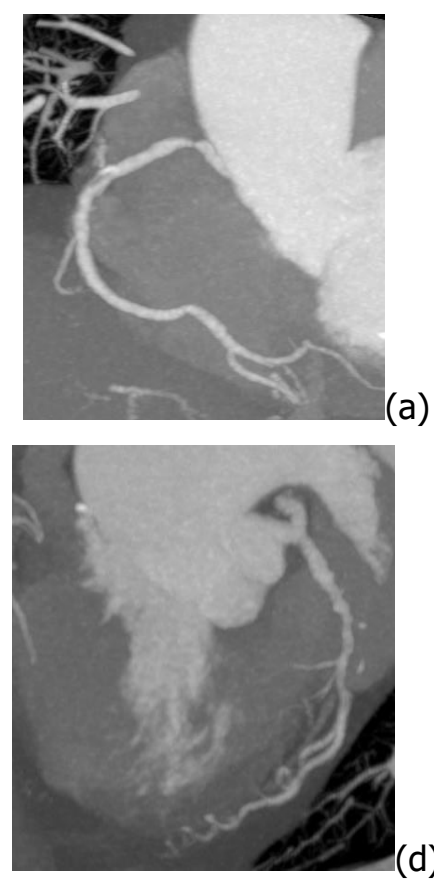
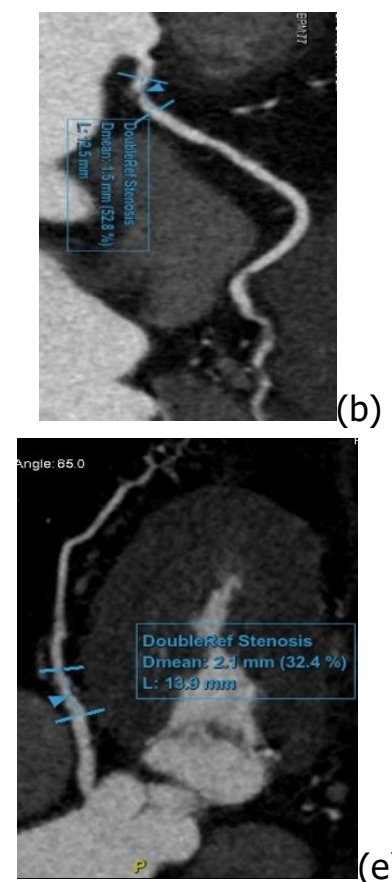
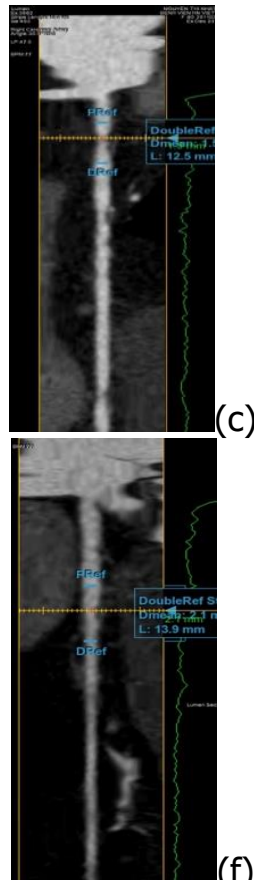

Hình 2. Bệnh nhân nữ 80 tuổi, MSCT 256 dãy mạch vành có tổng điểm vôi hoá = 95 điểm, dựng hinh MIP, mặt phẳng chếch và duỗi mạch.

ĐM vành phải $(R C A)$ trên MIP $(\mathrm{a})$ mặt phẳng chếch (b) và duỗi mạch $(\mathrm{c})$ thấy hẹp $52 \%$ đường kính. ĐM gian thất trước (LAD) trên MIP (d), mặt phẳng chếch (e) và duỗi mạch (f) thấy hẹp $32 \%$ đường kính.

Nghiên cứu của chúng tôi có $57,3 \%$ trường hợp có vôi hoá với VHTB là 351,2 2529,47 điểm (cao nhất là 2652 điểm), trong đó, chúng tôi không thấy có sự khác nhau về VHTB của nam là $421.5 \pm 583,37$ và của nữ là $273,8 \pm 448,01$ $(p=0,2)$ ở các BN có vôi hóa. Tuy nhiên, chúng tôi thấy có sự khác nhau về VHTB của các $B N<60$ tuổi là $46,5 \pm 144,35$ với các $B N \geq 60$ tuổi

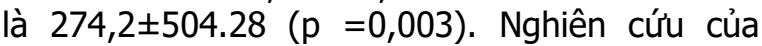
Schuhbeack và cS [2] có $60,5 \%$ trường hợp có vôi hoá với VHTB là 12 điểm. Nghiên cứu của Shaw và cs [5] có VHTB là 133. Theo Malguria và Shaw $(5,6)$, nam giới có điểm vôi hoá mạch vành cao hơn nữ giới, số lượng và tỷ lệ có xu hướng tăng lên theo tuổi. Tỷ lệ tử vong liển quan đến mạch vành ở các trường hợp > 60 tuổi cao hơn so với lứa tuổi trẻ hơn. Như vậy, tuy tỷ lệ BN vôi hoá mạch vành của chúng tôi thấp hơn nhưng VHTB lại cao hơn rất nhiều. Điều này cho thấy các $B N$ của chúng tôi thường là các trường hợp biểu hiện triệu chứng bất thường mới đến khám. Tuy vậy, xu hướng phân bố mức độ vôi hoá mạch vành theo giới tính và tuổi cũng phù hợp với các nghiên cứu khác.

Về mức độ vôi hoá chúng tôi gặp 42,7\% độ 0 (không vôi hoá); 25,3\% từ 1-99 điểm (độ 1); 17,3\% từ 100-399 điểm (độ 2); 8,7\% từ 400999 điểm (độ 3) và $6 \%$ có điểm $\geq 1000$ (độ 4). Nghiên cứu của Church và cs [1] trong 3,5 năm theo dõi, tỷ lệ tai biến tim mạch bao gôm tử vong vì bệnh mạch vành hoặc nhồi máu cơ tim ở những trường hợp không có vôi hoá mạch vành 
là $0,04 \%$. Khi điểm vôi hoá động mạch vành $\geq 100$ tương ứng với tăng tỷ lệ tai biến mạch vành lên $0,4 \%$. Mặt khác, trong số những người có nguy cơ thì nhóm có điểm vôi hoá $\geq 100$ sẽ tăng nguy cơ tai biến gấp đôi những trường hợp $<100$ điểm. Nghiên cứu của Shaw và cs [5] cho thây tỷ lệ sông sót trong vòng 5 năm là $99 \%$ với điểm vôi hóa $<10$ và giảm xuống còn $95 \%$ khi điểm vôi hóa $>1000$. Như vậy, điểm vôi hoá mạch vành có thể làm tăng nguy cơ tai biến do mạch vành ở những người có nguy cơ thấp trên lâm sàng đồng thời không có vôi hoá mạch vành tương ứng với nguy cơ thấp.

Theo Schuhbeak và cs [2] thì mức độ vôi hoá mạch vành là yếu tố để chỉ định chụp CLVT mạch vành tiêm thuốc vì khi tăng điểm vôi hoá sẽ làm tăng nguy cơ hẹp động mạch vành nên nếu vôi hoá ít thì nguy cơ hẹp thấp. Bên cạnh đó, khi có vôi hoá nhiêu thì sẽ gây khó khăn cho viêc đánh giá chính xác mức đô hẹp, có thể đánh giá hẹp quá mức đối với thực tế nên có thể phải làm thêm các thăm dò mạch vành khác.

Theo Van Dijk và cs [7], vôi hoá mạch vành năng sẽ có tiên lượng xấu, đồng thời tăng sự khó khăn cho thủ thuật can thiệp mạch vành. Vôi hoá nhiều có thể gây khó khăn trong đặt stent và thả stent không chính xác, stent nở không tốt sẽ có nguy cơ huyết khối và tắc mạch. Do đó, phát hiện mức độ vôi hoá mạch vành là điều cần thiết khi thực hiện điều trị. Cũng theo kết quả nghiên cứu này thì độ chính xác của chụp mạch vành để phát hiện vôi hoá là rất thấp. Do đó, tác giả khuyến cáo nên chụp CLVT để đánh giá mức độ vôi hoá mạch vành trước khi tiến hành can thiệp nhằm cải thiện khả năng tiếp cận điều trị.

Nghiên cứu sự liên quan giữa điểm vôi hóa và hẹp mạch vành chúng tôi thấy có sự khác biệt giữa điểm VHTB của các BN hẹp mạch vành $\geq 50 \%$ là $691,9 \pm 674,61$ và hẹp $<50 \%$ là $117,4 \pm 173,58(p<0,001)$. Đường cong ROC biểu thị liên quan điểm vôi hoá và mức độ hẹp mạch vành $\geq 50 \%$ có diện tích dưới đường cong (AUC) là 0,829 (95\%CI: 0,740-0,919). Ngưỡng điểm vôi hoá cho hẹp $\geq 50 \%$ là 196 điểm với độ nhay là 0,706 và độ đặc hiệu là 0,827 . Theo nghiền cứu của Schuhbeak và cs [2] thì ngưỡng điểm vôi hoá để có thể loại trừ các trường hợp hẹp mạch vành $<50 \%$ là 287 điểm. So sánh dưới nhóm cho thấy điểm này có xu hướng thấp hơn ở nam giới, ở các BN có nhịp tim nhanh >65 ck/phút hay ở trường hợp có chỉ số BMI (body mass index) $\geq 25 \mathrm{~kg} / \mathrm{m} 2$. Như vậy, ngưỡng điểm vôi hóa gây hẹp nặng của nhóm BN nghiên cứu của chúng tôi là thấp hơn.
Như vậy, chụp CLVT mạch vành có vai trò quan trọng trong phát hiện mức độ vôi hóa và hẹp mạch vành. Do mức độ vôi hóa mạch vành là yếu tố dự đoán độc lập của hẹp mạch vành, nên khi điểm vôi hóa mạch vành thấp thì sẽ có nguy cơ thấp bị hẹp mạch nên cũng không cần phải thực hiện thêm các thăm dò khác.

\section{KẾT LUÂ̂N}

Cắt lớp vi tính đa dãy đóng vai trò quan trọng trong phát hiện vôi hóa mạch vành. Điểm vôi hóa mạch vành tăng lên theo tuổi và có sự liên quan đến mức độ hẹp mạch vành trên lâm sàng. Do đó, điểm vôi hóa mạch vành có thể là dấu hiệu dự báo nguy cơ tai biến do bệnh mạch vành trong tương lai và là căn cứ để chỉ định làm thêm các thăm dò mạch vành khác.

\section{TÀI LIỆU THAM KHẢO}

1. Church TS, Levine BD, McGuire DK, LaMonte MJ, FitzGerald SJ, Cheng YJ, et al (2007). Coronary artery calcium score, risk factors, and incident coronary heart disease events. Atherosclerosis; 190(1):224-31.

2. Schuhbaeck A, Schmid J, Zimmer T, Muschiol G, Hell MM, Marwan M, et al (2016). Influence of the coronary calcium score on the ability to rule out coronary artery stenoses by coronary CT angiography in patients with suspected coronary artery disease. J Cardiovasc Comput Tomogr; 10(5): 343-50.

3. Gambre AS, Liew C, Hettiarachchi G, Lee SSG, MacDonald M, Kam CJW, et al (2018). Accuracy and clinical outcomes of coronary CT angiography for patients with suspected coronary artery disease: a single-centre study in Singapore. Singapore Med J;59(8):413-8.

4. Zreik M, van Hamersvelt RW, Wolterink JM, Leiner T, Viergever MA, Isgum I. A. (2019). Recurrent CNN for Automatic Detection and Classification of Coronary Artery Plaque and Stenosis in Coronary CT Angiography. IEEE Trans Med Imaging;38(7):1588-98.

5. Shaw LJ, Raggi $P$, Schisterman E, Berman DS, Callister TQ (2003). Prognostic Value of Cardiac Risk Factors and Coronary Artery Calcium Screening for All-Cause Mortality. Radiology;228(3):826-33.

6. Malguria $\mathbf{N}$, Zimmerman $S$, Fishman EK (2018). Coronary Artery Calcium Scoring: Current Status and Review of Literature. J Comput Assist Tomogr;42(6):887-97.

7. Van Dijk JD, Shams MS, Ottervanger JP, Mouden M, van Dalen JA, Jager PL (2017). Coronary artery calcification detection with invasive coronary angiography in comparison with unenhanced computed tomography. Coron Artery Dis [Internet];28(3): 246-52.

8. Plank F, Burghard $P$, Friedrich G, Dichtl W, Mayr A, Klauser A, et al (2016). Quantitative coronary CT angiography: absolute lumen sizing rather than \%stenosis predicts hemodynamically relevant stenosis. Eur Radiol;26(11):3781-9. 